\title{
Determination of Allowable Capacity of Distributed Generation with Protection CoOrdination Consideration
}

\section{Titti Saksornchai* and Bundhit Eua-arporn}

\author{
Department of Electrical Engineering, \\ Faculty of Engineering, Chulalongkorn University, \\ Bangkok, Thailand 10330
}

Email: tumcus@gmail.com*,bundhit.e@chula.ac.th

\section{ABSTRACT}

The presence of distributed generation (DG) provides considerable benefits from both engineering and economic viewpoints. However, it changes radial configuration of the distribution feeders. Consequently it may cause coordination failure to existing protection system which is originally set based on radial configuration. In addition, high penetration level of DG may increase feeder loss, and cause system voltage profile out of a required range.

This paper presents an optimization based method to calculate maximum allowable capacity of a DG considering a set of constraints formulated to maintain protection system coordination. In addition feeder loss and system voltage constraints are also taken into account. With the developed methodology, the maximum DG capacity which does not provide adverse effects to the existing system, i.e. violate protection coordination, increase feeder loss, and cause voltage violation, can be obtained.

\section{KEYWORDS}

distribution system, distributed generation, protection coordination 


\section{Introduction}

Nowadays, the number of DGs continually increases. In general, a DG provides several benefits to social and distribution network, i.e. additional generation resources, voltage regulation, loss reduction. However, the DG does increase fault levels in the distribution system, change network radial configuration. Consequently, it has influence on existing protection systems [1], [2].

With a high penetration of DGs, the fault level increases and the path in which the fault current flows is altered. As a result, the distribution network is no longer a passive circuit. It becomes active due to the embedded DG sources. Therefore, the DG can cause adverse effects to the existing protection system, resulting in coordination failure and consequently reducing system reliability.

It is widely understood that high level penetration of DGs may increase feeder loss. Moreover, it can cause voltage violation which may provide adverse effect to electrical equipment [3], [4].

This paper presents a methodology to determine the maximum allowable capacity of a DG to be connected to a medium voltage distribution feeder such that coordination failure of the existing system protection will be avoided. Additionally, it also takes into account other key criteria, i.e. power loss and system voltage requirement which should be maintained within a specific range.

The content of this paper is divided into seven sections. The next section presents the causes of protection system miscoordination due to the DG, followed by problem formulation. The following section presents the developed methodology to determine an allowable DG capacity which will not cause protection coordination failure, increase of loss, and system operating voltage profile violation. Then, a test system and the setting of protective devices will be described. The obtained results and discussions are then provided in the following section. The final section will then be provided with conclusion.

\section{DG Impact on Distribution Protection System}

The presence of a DG in an MV distribution network generally changes its radial configuration, for which the protection system coordination has been originally set up. Consequently, when a fault occurs, it may cause miscoordination in the existing protection system. In this section we investigate the possibility of the miscoordination between fuse and recloser due to the DG. It has been shown in [1], [2] that investigation of the protection coordination can be classified into two cases according to the DG locations, i.e. behind and in front of the recloser.

\section{A. DG behind recloser}

\section{A.1 Fault in the lateral located behind recloser}

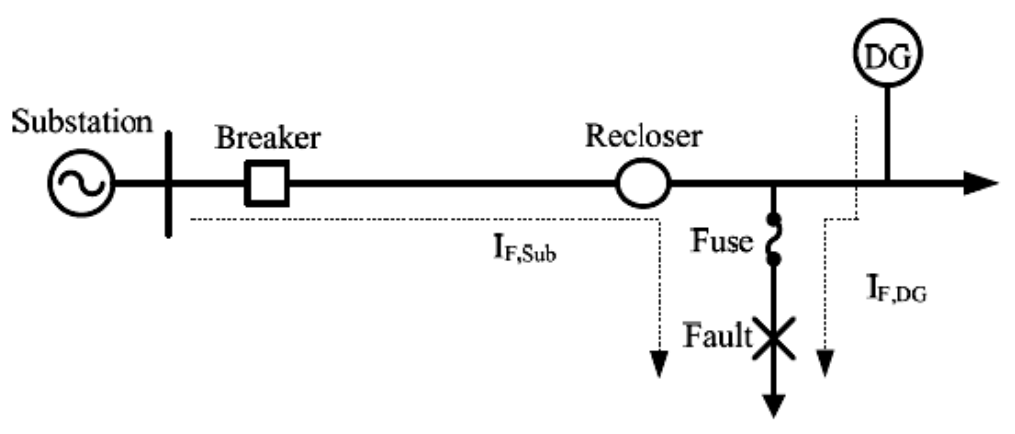


Figure 2

Fault in the lateral located in front of recloser
For a fuse saving scheme application, the fast curve of a recloser must operate before fuse minimum melting time (MMT) curve of the fuse close-in fault [5]. This scheme will save fuse from unnecessary operation under the condition of a temporary fault, which is self cleared by de-energizing the circuit by the recloser's fast curve operation.

If a DG is installed behind a recloser and a fault occurs in the lateral located behind the recloser, as shown in Figure 1, the recloser and fuse will perceive different fault currents. The fuse will perceive a higher fault current, as a combination of fault currents from the system and the DG. In this case, there is a chance that the fuse will operate before the operating time defined by the fast curve of the recloser. Consequently the temporary fault may result in the same impact to the system as the permanent fault. For a permanent fault, fuse operating curve is generally well coordinated with a slow curve of the recloser.

\section{A.2 Fault in the lateral located in front of recloser}

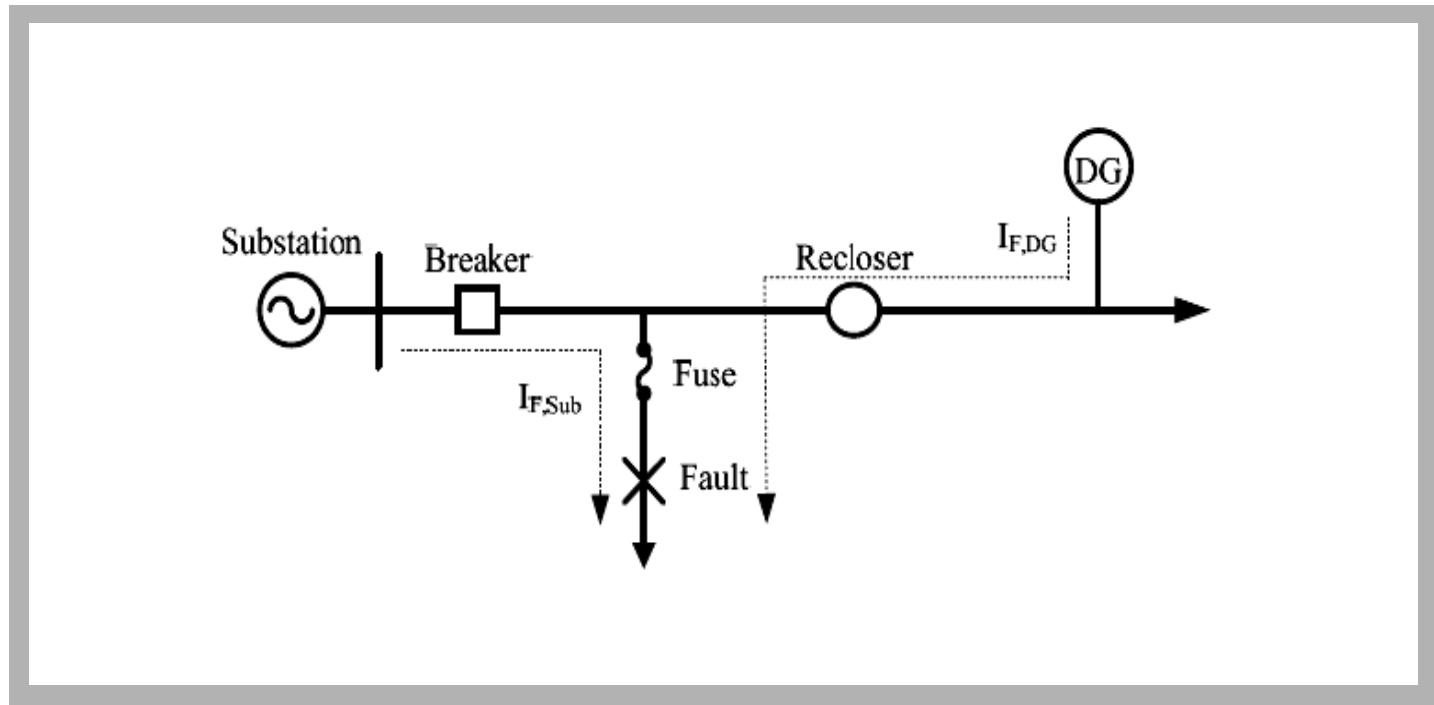

If a DG is installed behind a recloser and a fault occurs in the lateral located in front of the recloser, as shown in Figure 2, there will be a fault current feeding from the DG passing through the recloser in the back-flow direction. If the recloser is a nondirectional type, there is a chance that the fast curve of the recloser may operate before the lateral fuse can clear out the fault. This will result in unnecessary momentary interruption to all customers behind the recloser, which reduces system reliability.

\section{B. DG in front of recloser}

\section{B.1 Fault in the lateral located behind recloser}

Figure 3

Fault in the lateral located behind recloser

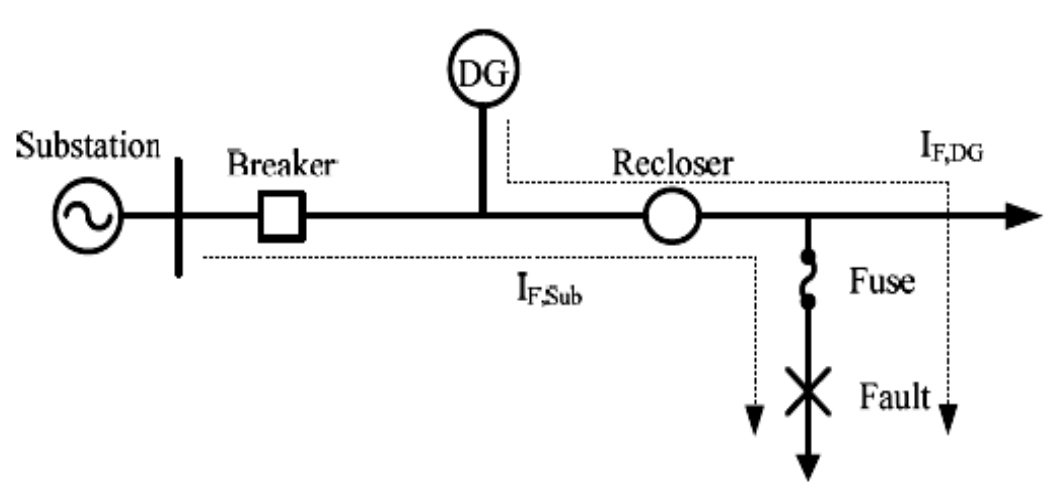


If a DG is installed in front of the recloser and a fault occurs in the lateral placed behind the recloser, as shown in Figure 3 , the recloser and fuse will perceive the same fault current. However the fault current is higher compared to the case of with no connected DG. Due to the fact that the fuse saving scheme is generally designed to work to a certain fault level, there is a chance that additional fault current from the DG may cause miscoordination between fuse and recloser. Again, it has impact only for a temporary fault.

\section{B.2 Fault in the lateral located in front of recloser}

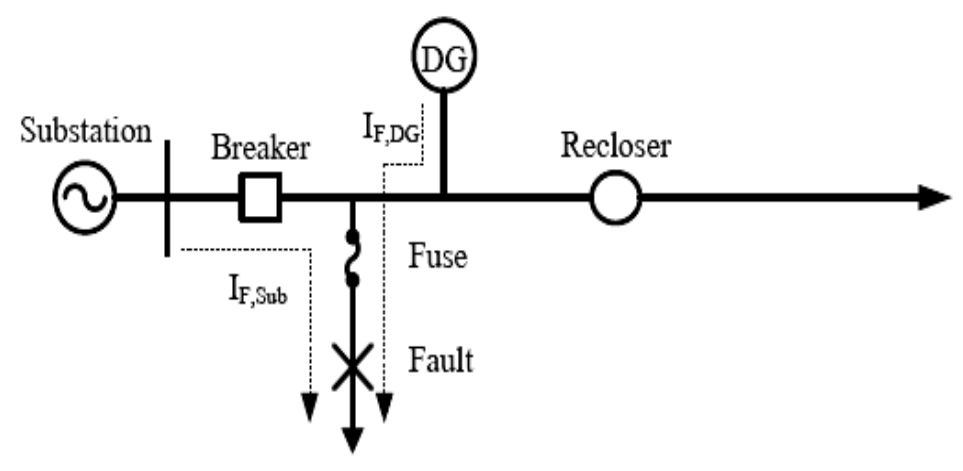

Figure 4

Fault in the lateral located in front of recloser

If a DG is installed in front of the recloser and a fault occurs on the lateral located in front of the recloser, as shown in Figure 4, protection miscoordination is unlikely. In this case, primary concern is the fuse interruption capacity, as there is additional fault current fed through from the DG.

\section{B.3 Fault in the lateral behind recloser at a nearby feeder}

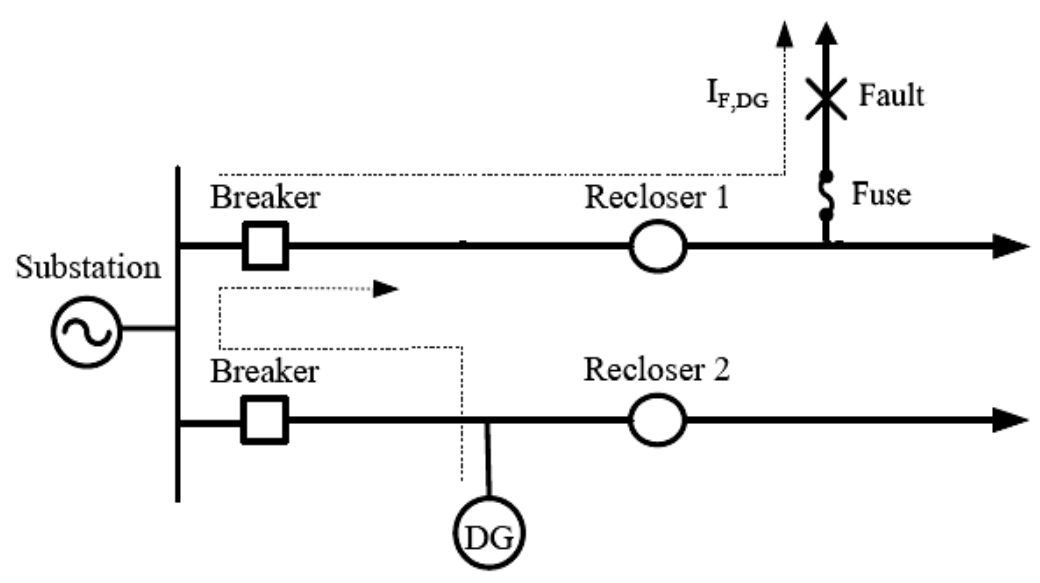

Figure 5

Fault in the lateral behind recloser at a nearby feeder

If a DG is installed in front of a recloser and there is a fault on a lateral behind the recloser on a nearby feeder, as shown in Figure 5, both recloser and fuse will perceive a higher fault current compared to the case with no DG. If this incremental fault current is large enough, the designed fuse saving scheme may not be achieved, which is similar to case B.1. 
From all the above investigation, the impact from a DG to protection coordination between fuse and recloser can be summarized in Table 1.

Case

DG position

Fault location

A.1

Behind recloser

Behind recloser

A.2

Behind recloser

In front of recloser

B.1

In front of recloser

Behind recloser

B. 2

In front of recloser

In front of recloser

B.3

In front of recloser

Behind recloser

(Nearby feeder)

\section{Fault current}

$$
\begin{gathered}
I_{R}=I_{F, \text { Sub }} \\
I_{\text {Fuse }}=I_{F, \text { Sub }}+I_{F, D G} \\
I_{R}=I_{F, D G} \\
I_{\text {Fuse }}=I_{F, \text { Sub }}+I_{F, D G} \\
I_{R}=I_{F, \text { Sub }}+I_{F, D G} \\
I_{\text {Fuse }}=I_{F, \text { Sub }}+I_{F, D G} \\
I_{R}=0 \\
I_{\text {Fuse }}=I_{F, \text { Sub }}+I_{F, D G} \\
I_{R}=I_{F, \text { Sub }}+I_{F, D G} \\
I_{\text {Fuse }}=I_{F, \text { Sub }}+I_{F, D G}
\end{gathered}
$$

Table 1

Summary of the possible miscoordination pattern

Where $\quad \begin{aligned} & I_{R}=\text { Fault current passing through recloser } \\ & I_{\text {Fuse }}=\text { Fault current passing through fuse } \\ & I_{F, \text { Sub }}=\text { Fault current contribution from substation } \\ & I_{F, D G}=\text { Fault current contribution from DG }\end{aligned}$

In fact, a DG installed in front of a recloser can also cause protection miscoordination for a fault on a lateral in front of the recloser on a nearby feeder. For this case, there is an additional fault current feeding from the DG through the circuit breaker at the substation in back flow direction. If the relay at the substation is a non-directional type, the circuit breaker may unnecessary operate with this back flow fault current. Nonetheless, the above problem is almost impossible to occur. The fault current feeding from the DG is typically small compared to the fault current from the substation. As a result, with time characteristic of over current relay, it will take a fairly long time for the circuit breaker to operate. In addition, the lateral fuse with a higher fault current contributing from both substation and DG will operate even faster. Therefore, the lateral fuse in front of the recloser on a nearby feeder always clear fault before the circuit breaker at substation. Therefore, the installed DG generally has no impact in this case.

\section{Problem Formulation}

The objective of this study is to identify the maximum allowable capacity of a DG which does not increase feeder loss, violate required voltage level, or cause protection coordination failure. The problem is formulated as a minimization problem to obtain the maximum allowable capacity of a DG to be connected to a feeder.

This section will begin with the defined objective function. Then, sets of constraints, i.e. voltage, power loss, and protection coordination, are defined and developed. The calculation procedure is then proposed.

\section{A. Assumption}

The DG in this paper is assumed to be a synchronous type. For fault calculation, the total sub-transient reactance including step-up transformer of the DG is assumed to be 0.25 per unit based on a typical value [5], [6]. It is also assumed that the DG capacity is limited to 10 MW [7], which is applied as the upper limit for the search range of the solution. A fault study is performed based on the Z-bus method [8] - [10]. For simplicity, only three-phase faults are considered in this paper. 
The number of DG in this study is limited to one DG per feeder. In addition, the possible connection point of the DG is restricted to only on the primary feeder. For the required load flow analysis, the DG is assumed to operate with a unity PF control mode and is modeled as a PQ bus.

\section{B. Objective function and constraints}

The objective is to determine the maximum allowable capacity of a DG, which can be written as

$$
\begin{aligned}
& \operatorname{Max}\left(P_{D G}\right)=-\operatorname{Min}\left(-P_{D G}\right) \\
& \text { Where } \quad P_{D G}=\text { Output of DG in MW }
\end{aligned}
$$

The constraints are classified into three categories, i.e. system voltage, feeder loss, and protection coordination. The constraint equations can be presented below.

\section{B.1 Voltage constraint}

The voltage at each load point should be within an acceptable range, which is defined to be 0.95-1.05 p.u. in this paper. The conditions can be written as

$$
\begin{aligned}
& V_{i}-1.05 \leq 0, \quad \forall i \in B \\
& 0.95-V_{i} \leq 0, \quad \forall i \in B
\end{aligned}
$$

where $\quad V_{i}=$ voltage at bus $\mathrm{i}$, and

$$
B=\text { set of bus number. }
$$

\section{B.2 Loss constraint}

In this paper, the DG capacity allowed to be connected to the feeder will not increase loss of the feeder. The condition can be defined as

$$
L-L_{\text {base }} \leq 0
$$

where

$$
\begin{aligned}
& L \quad=\text { total line loss of the system with a DG, and } \\
& L_{\text {base }}=\text { total line loss of the system without DG. }
\end{aligned}
$$

\section{B.3 Protection coordination constraint}

Protection constraints are developed to cope with the coordination failure based on the investigation described in Section II.

Referred to Case A.1, the coordination failure may occur if the lateral fuse perceives more fault current than the recloser does. In general the fuse saving scheme will be fail if the fault current is higher than a certain value. Therefore, the condition for not losing coordination of the fuse saving scheme is to have the recloser fast curve operating time less than the minimum melting time of the fuse. This constraint is applied when the DG and fault location is as shown in Figure 1, which can be written as (3.5).

$$
T_{R f}\left(I_{F, \text { Sub }}\right)-M M T_{F}\left(I_{F, \text { Sub }}+I_{F, D G}\right) \leq 0
$$

where $\quad T_{R f}\left(I_{F}\right) \quad=$ recloser fast curve operating time at $I_{F}$ $M M T_{F}\left(I_{F}\right)=$ fuse minimum melting time at $I_{F}$

In Case B.1, the problem is similar to that of Case A.1, however the recloser and fuse will perceive the same fault current. Therefore, to keep the fuse saving scheme coordinated, the constraint below is required.

$$
T_{R f}\left(I_{F, S u b}+I_{F, D G}\right)-M M T_{F}\left(I_{F, \text { Sub }}+I_{F, D G}\right) \leq 0
$$

For Case B.2, the concern is about the fuse interruption rating. Since the DG can lead to higher fault current levels, interrupting current should be taken into account. 
In this paper, the fuse interrupting capacity is chosen to be $10 \mathrm{kA}$, from which the constraint according to Figure 4 will be

$$
I_{\text {Fuse }}-10,000 \leq 0
$$

It should be noted that equation (3.7) is also a constraint for all cases described in Section II.

For Case A.2, the problem occurs due to the DG's fault current passing through recloser in the back flow direction. If the DG's fault current is sufficiently high due to its capacity and the recloser is a non-directional type, the recloser may operate with its fast curve before the fuse can clear the fault. This will cause unnecessary momentary interruption to all customers in the feeder behind the recloser. Therefore, fault contribution from the DG should not cause recloser to operate in the case of back flow direction. Thus, for the condition in Figure 2, the constraint can be written as

$$
I_{R}-I_{R, \text { Pickup }} \leq 0
$$

where $\quad I_{R, \text { Pickup }}=$ Pick up setting of recloser

As for the last case of B.3, the DG located close to a substation can also interfere with the fuse saving scheme of the nearby feeder. This situation is similar to Case B.1 but only the DG is connected to the other feeder. Similar to the DG in front of a recloser, this DG can also increase fault currents to a nearby feeder perceived by recloser and fuse. As a result, the fuse saving scheme may be violated.

Therefore, for a connected DG in front of the recloser and a fault occurs at lateral behind the recloser of the other feeder, equation (3.6) must be considered.

Based on all the above analysis, the protection constraints to maintain the protection

\begin{tabular}{|c|c|c|c|c|}
\hline & Case & DG position & Fault location & Fault current \\
\hline & A.1 & Behind recloser & Behind recloser & (3.5) \\
\hline & A. 2 & Behind recloser & In front of recloser & (3.8) \\
\hline \multirow{3}{*}{$\begin{array}{l}\text { Table } 2 \\
\text { Summary of } \\
\text { protection } \\
\text { constraints }\end{array}$} & B.1 & In front of recloser & Behind recloser & (3.6) \\
\hline & B.2 & In front of recloser & In front of recloser & (3.7) \\
\hline & B.3 & In front of recloser & $\begin{array}{l}\text { Behind recloser } \\
\text { (Nearby feeder) }\end{array}$ & (3.6) \\
\hline
\end{tabular}
coordination can be summarized in Table 2 . 


\section{Maximum Allowable Capacity Determination}

This section presents a proposed procedure to identify the maximum allowable capacity of the DG at each location along the distribution feeder subjected to the above mentioned constraints. The procedure is illustrated by figure 6 , and can be described below.

1) Run a based case power flow of the existing system and store the results.

2) Select DG connected at bus $i$ and a defined fault location at bus $j$, then select a proper protection constraint according to Table 2.

3) Apply a direct search method to the objective function in (3.1) and constraints defined from 2) to search for maximum allowable DG capacity at bus i with respect to a fault at bus $\mathrm{j}$. Store the result.

4) Repeat 3) by fixing the DG connected to bus i and change a defined fault location at bus $j$ to every bus in the system.

5) Based on the obtained results from 3) - 4), select the minimum value as the solution for the maximum allowable DG capacity connected at bus $\mathrm{i}$.

6) Repeat 2) - 5) for all possible DG locations.

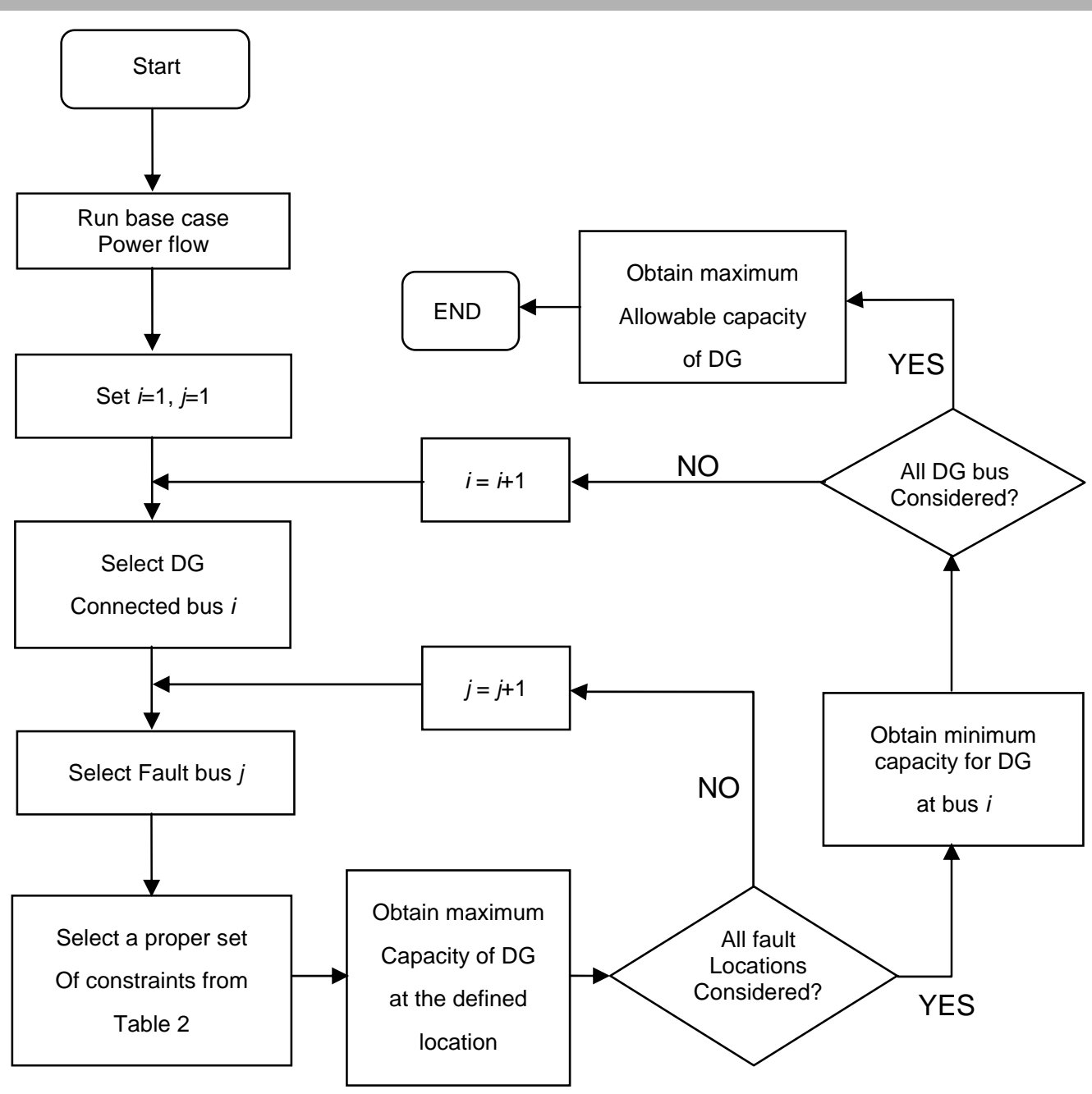

Figure 6 Procedure for determining maximum allowable capacity of DG 


\section{The Test System}

This section describes about the distribution network used as the test system in this paper. Details of protection settings are also provided.

\section{A. Test system}

A modified RBTS BUS 2 [11] shown in Figure 7 is used as the test system in this paper. A 200 MVA fault level is assumed at the station bus (25 MVA transformer with impedance voltage $=12.5 \%)$. In this test system, the line length is assumed to be increased by five times of the original data whereas the operating voltage is modified from 11 to $22 \mathrm{kV}$ to be comparable with a typical characteristic of a distribution feeder of the Provincial Electricity Authority of Thailand.

In Figure 7, LP is represented for load point, and "R" is for a mid-line recloser. The number followed by capitalized letter indicates possible DG locations on each feeder. As an example, "2B" represents the possible DG location is at point B in Feeder 2. All necessary parameters, e.g. impedance, line length, and load are shown in Tables 3- 6. It was found from the base case analysis that the total system loss with no presence of DG is of $0.6094 \mathrm{MW}$

Figure 7

Test system RBTS BUS2 [11]

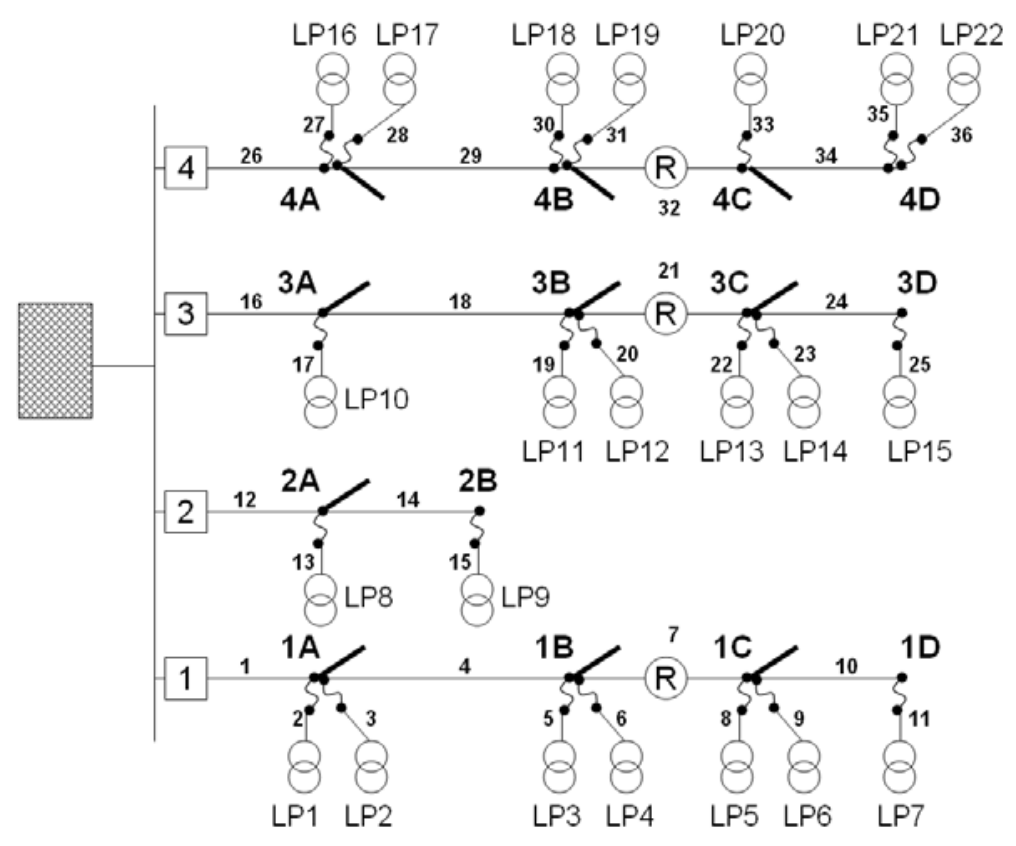

Table 3

Feeder length data

\begin{tabular}{|c|c|c|}
\hline No. & Feeder length $\mathbf{( k m )}$ & Branch no. \\
\hline $\mathbf{1}$ & 3 & $2,6,10,14,17,21,25,28,30,34$ \\
\hline $\mathbf{2}$ & 3.75 & $1,4,7,9,12,16,19,22,24,27,29,32,35$ \\
\hline $\mathbf{3}$ & 4 & $3,5,8,11,13,15,18,20,23,26,31,33,36$ \\
\hline
\end{tabular}




\begin{tabular}{|c|c|}
\hline Type & Impedance (Ohm) \\
\hline Main Feeder & $0.211+0.414 \mathrm{j}$ \\
\hline Lateral Feeder & $0.341+0.456 \mathrm{j}$ \\
\hline
\end{tabular}

Table 4

Feeder impedance

(Ohm)

\begin{tabular}{|c|c|c|c|}
\hline \multirow{2}{*}{$\begin{array}{c}\text { Load Point } \\
\text { (LP) }\end{array}$} & Customer type & \multicolumn{2}{|c|}{ Peak demand } \\
\cline { 3 - 4 } & & $\begin{array}{c}\text { Real power } \\
\text { (MW) }\end{array}$ & $\begin{array}{c}\text { Reactive } \\
\text { power (MVAR) }\end{array}$ \\
\hline $1-3,10,11$ & Residential & 0.8668 & 0.6934 \\
\hline $12,17-19$ & Residential & 0.7291 & 0.5833 \\
\hline 8 & Medium Industry & 1.6279 & 1.3023 \\
\hline 9 & Medium Industry & 1.8721 & 1.4977 \\
\hline $4,5,13,14,20,21$ & State agency & 0.9167 & 0.7334 \\
\hline $6,7,15,16,22$ & Commercial & 0.75 & 0.6 \\
\hline \multicolumn{2}{r}{ Total } & & 16.0006 \\
\hline
\end{tabular}

\begin{tabular}{|c|c|c|c|}
\hline \multirow{2}{*}{$\begin{array}{c}\text { Load Point } \\
\text { (LP) }\end{array}$} & $\begin{array}{c}\text { Load Point } \\
\text { (LP) }\end{array}$ & \multicolumn{2}{|c|}{ Peak demand } \\
\cline { 3 - 4 } & Residential & $\begin{array}{c}\text { Real power } \\
\text { (MV) }\end{array}$ & $\begin{array}{c}\text { Reactive } \\
\text { power (MVAR) }\end{array}$ \\
\hline 1 & Residential & 3.9338 & 4.747 \\
\hline 2 & Medium Industry & 5.0461 & 2.8 \\
\hline 3 & Medium Industry & 5.5207 & 4.0369 \\
\hline 4 & Total & 20.0006 & 4.4167 \\
\hline
\end{tabular}

Table 5

Load information
Table 6

Load summary per feeder 


\section{B. Protection coordination}

There are two key types of protective devices used in the test system, i.e. recloser and fuse. It is assumed that relays and circuit breakers are installed at the beginning of each feeder and well coordinated with other protective devices. A non-directional type recloser with application of fuse saving scheme, is placed at the middle of each feeder except for Feeder 2. Fuse link is assumed to be of type K, i.e. fast type.

Protection coordination is set according to a general practice [12],[13]. For simplicity, only the three-phase faults are considered in this paper. The phase setting and operating curve of the protective devices can be summarized in Table 7. An example of time-over current coordination of Feeder 1 is presented in Figure 8.

Table 7

Summary of protective device settings

\begin{tabular}{|c|c|c|c|c|c|}
\hline \multirow{2}{*}{ Feeder } & \multirow{2}{*}{$\begin{array}{l}\text { Circuit Breaker } \\
\text { (shown in primary) }\end{array}$} & \multirow{2}{*}{ Recloser } & \multicolumn{3}{|c|}{ Fuse Type K (Branch) } \\
\hline & & & $40 A$ & $65 \mathrm{~A}$ & $100 \mathrm{~A}$ \\
\hline 1 & $\begin{array}{l}\text { Curve }=S \mid \\
\mid \mathrm{p}=411 \mathrm{~A}, \text { Dial }=0.1\end{array}$ & $\begin{array}{l}\text { F_curve }=101 \\
\text { S_curve }=116 \\
\text { Ip }=260 A\end{array}$ & $2,3,5,6$ & $8,9,11$ & - \\
\hline 2 & $\begin{array}{l}\text { Curve=El } \\
\mid p=300 A, \text { Dial }=0.2\end{array}$ & None & - & - & 13,15 \\
\hline 3 & $\begin{array}{l}\text { Curve=SI } \\
\mid p=349, \text { Dial }=0.15\end{array}$ & $\begin{array}{l}\text { F_curve }=101 \\
\text { S_curve }=116 \\
\text { Ip }=270 A\end{array}$ & $17,19,20$ & $22,23,25$ & - \\
\hline 4 & $\begin{array}{l}\text { Curve }=S \mid \\
\mid \mathrm{p}=383 \mathrm{~A}, \text { Dial }=0.1\end{array}$ & $\begin{array}{l}\text { F_curve }=101 \\
\text { S_curve }=116 \\
\text { Ip=260A }\end{array}$ & $\begin{array}{c}27,28,30 \\
31\end{array}$ & $33,35,36$ & - \\
\hline
\end{tabular}

Figure 8

Time

coordination

curve of

protective device

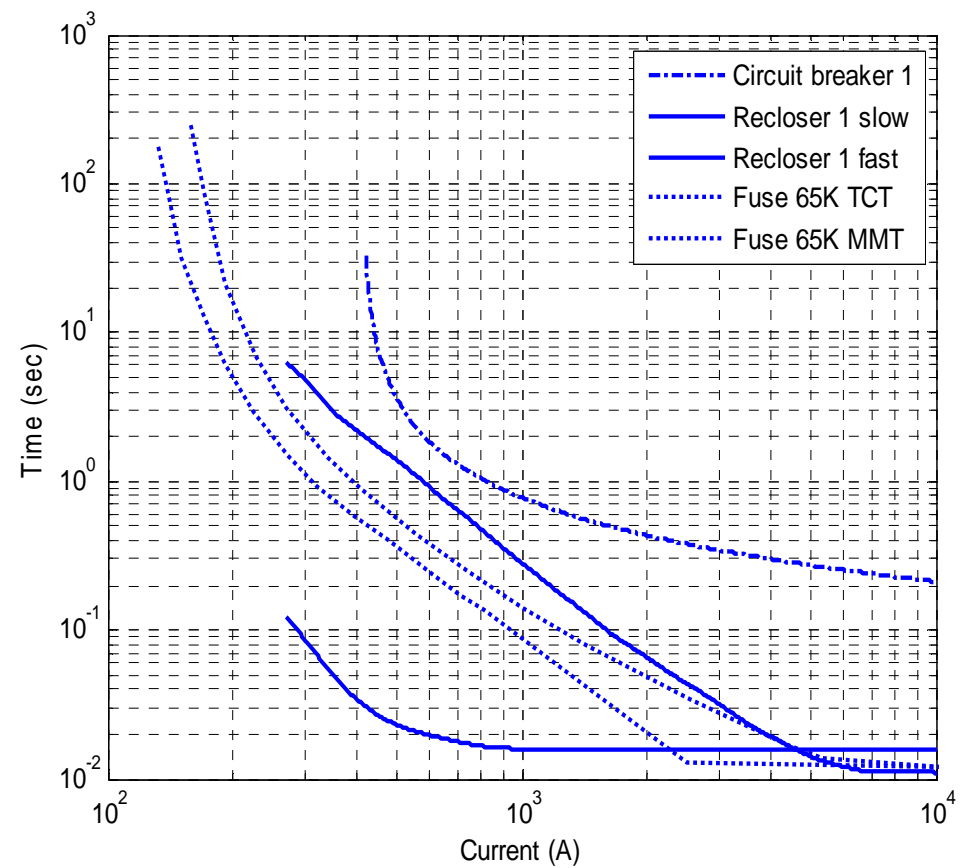


From Figure 8, it can be seen that fuse saving scheme is possible up to a certain fault level, which is at the intersection point between "Recloser 1 fast" curve and "Fuse 65K MMT", i.e. approximately $2.5 \times 10^{3}$ Ampere.

\section{Results and Discussions}

This section presents all the results obtained from the proposed method. The analysis is divided into 3 cases according to constraint considerations, i.e.
1) line loss constraint,
2) protection coordination constraint, and
3) protection coordination and line loss constraints.

The results of the maximum allowable capacity of the DG at each location of the test system are shown in Table 8 . In addition, the percentage of the line loss reduction compared to the base case with no DG is also included.

\begin{tabular}{|c|c|c|c|c|c|}
\hline \multirow[t]{2}{*}{ Feeder } & \multirow{2}{*}{$\begin{array}{l}\text { DG } \\
\text { location }\end{array}$} & \multirow{2}{*}{$\begin{array}{l}\text { In front of } I \\
\text { behind Recloser }\end{array}$} & \multicolumn{3}{|c|}{$\begin{array}{c}\text { Maximum allowable DG size capacity (MW) I } \\
\text { Loss reduction (\%) }\end{array}$} \\
\hline & & & Case 1 & Case 2 & Case 3 \\
\hline \multirow{4}{*}{1} & $1 \mathrm{~A}$ & In front & $10.00 / 6.44 \%$ & $10.00 / 6.44 \%$ & $10.00 / 6.44 \%$ \\
\hline & $1 B$ & In front & $10.00 / 2.77 \%$ & $10.00 / 2.77 \%$ & $10.00 / 2.77 \%$ \\
\hline & $1 C$ & Behind & 8.62 / 0.00\% & $2.56 / 13.14 \%$ & $2.56 / 13.14 \%$ \\
\hline & 1D & Behind & $7.10 / 0.00 \%$ & $2.63 / 12.62 \%$ & $2.63 / 12.62 \%$ \\
\hline \multirow{2}{*}{2} & $2 \mathrm{~A}$ & In front & 7.22 / 0.00\% & $10.00 /-7.17 \%$ & $7.22 / 0.00 \%$ \\
\hline & $2 B$ & In front & $5.70 / 0.00 \%$ & $10.00 /-19.74 \%$ & $5.70 / 0.00 \%$ \\
\hline \multirow{4}{*}{3} & $3 A$ & In front & $10.00 / 1.59 \%$ & $10.00 / 1.59 \%$ & $10.00 / 1.59 \%$ \\
\hline & $3 B$ & In front & $9.56 / 0.00 \%$ & $10.00 /-2.40 \%$ & $9.56 / 0.00 \%$ \\
\hline & $3 C$ & Behind & $8.33 / 0.00 \%$ & 2.64 / 12.05\% & $2.64 / 12.05 \%$ \\
\hline & $3 D$ & Behind & $6.54 / 0.00 \%$ & 2.74 / 11.26\% & $2.74 / 11.26 \%$ \\
\hline \multirow{4}{*}{4} & $4 \mathrm{~A}$ & In front & $10.00 / 4.53 \%$ & $10.00 / 4.53 \%$ & $10.00 / 4.53 \%$ \\
\hline & 4B & In front & $10.00 / 0.07 \%$ & $10.00 / 0.07 \%$ & $10.00 / 0.07 \%$ \\
\hline & $4 C$ & Behind & 8.44 / 0.00\% & $2.66 / 13.29 \%$ & $2.66 / 13.29 \%$ \\
\hline & 4D & Behind & $7.37 / 0.00 \%$ & $2.74 / 13.90 \%$ & $2.74 / 13.90 \%$ \\
\hline
\end{tabular}

Table 8

Simulation results 
From the results in Table 8, protection coordination clearly has impact in determining the maximum allowable capacity. If the protection coordination is ignored, i.e. only system voltage and line loss are considered, the results of the maximum allowable DG capacity will become larger. For example, considering Feeder 3 without protection coordination constraint as of Case 1, the maximum allowable capacity of a DG at node 3D is $6.54 \mathrm{MW}$, which may, however, cause protection coordination failure. In Case 3 , if the protection coordination is taken into account, the maximum allowable capacity of a DG at node 3D reduces to 2.74 MW.

In case of neglecting the line loss constraint, it may result in a higher allowable capacity. As an example, the maximum allowable DG capacity at node $2 \mathrm{~B}$ is $5.70 \mathrm{MW}$ as of Case 3 . However, it increases to $10 \mathrm{MW}$ when the loss constraint is neglected as of Case 2 with the increase of system loss by $19.74 \%$.

In addition, it can be noticed that the maximum allowable size of DGs located in front of the recloser is larger than that those of located behind the recloser. Considering Feeder 1, which has a mid-line recloser and with all constraints being applied as in Case 3 , the results in Table 8 show that the maximum capacity located in front of recloser, i.e. nodes $1 \mathrm{~A}$ and $1 \mathrm{~B}$, is $10 \mathrm{MW}$. In constrast, the maximum allowable capacity of a DG located behind the recloser of Feeder 1, i.e. nodes $1 \mathrm{C}$ and $1 \mathrm{D}$, are in the range of 2.5-2.6 MW. Similar results can be seen with Feeders 3 and 4 . Figure 9 summarizes the maximum allowable capacity of the DG located in front of and behind recloser for each feeder.

Figure 9 Comparison among the maximum allowable capacities of DGs located in front and behind the recloser of each feeder
Figure 10 Maximum allowable capacity and its associated \% loss reduction
Location
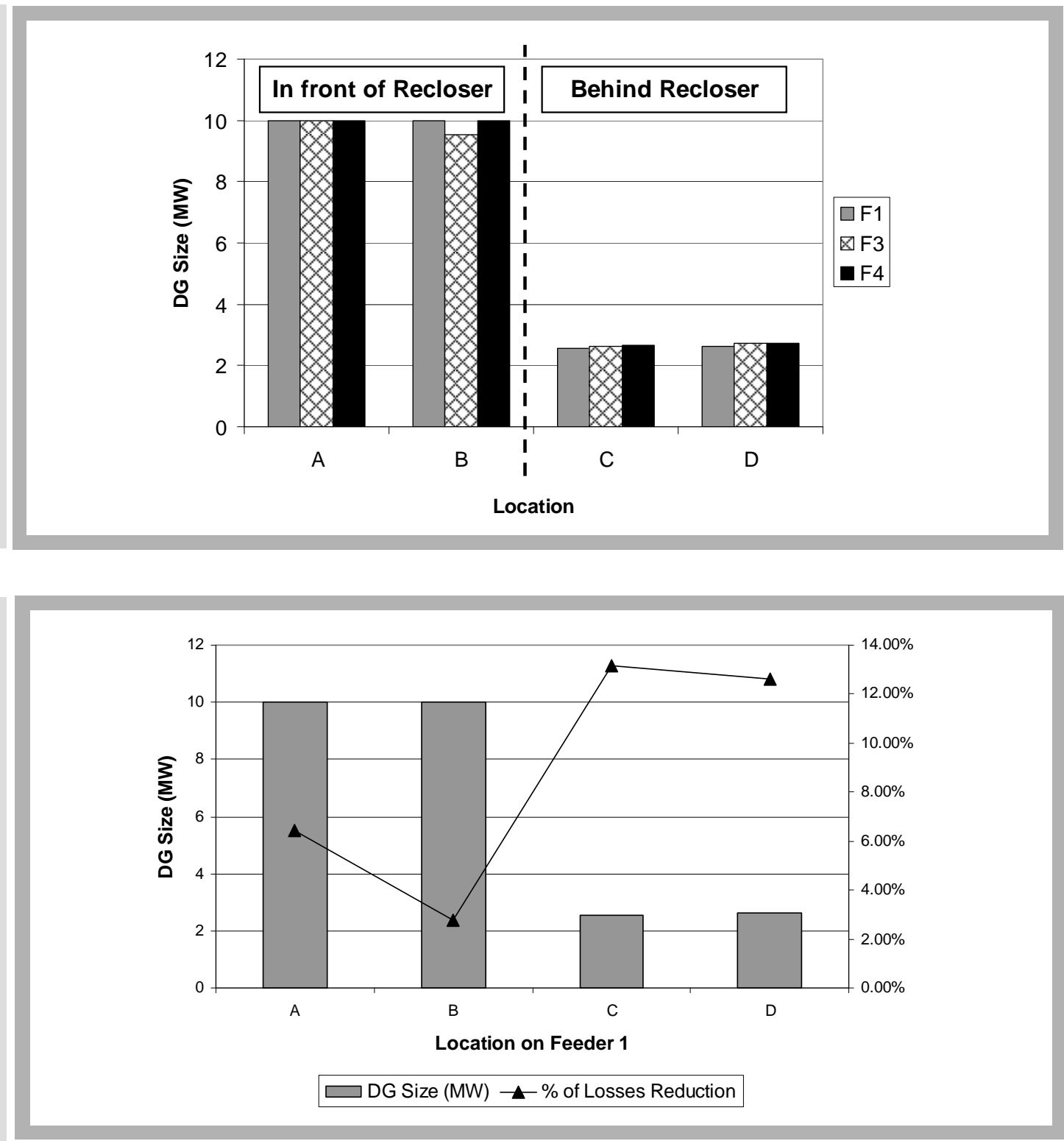
Figure 10 illustrates maximum allowable capacity of a DG for each location of Feeder 1 and its associated loss reduction of Case 3. The figure shows that although the maximum allowable capacity of the DG behind the recloser is rather small, however the percentange of loss reduction is high, to an approximated value of $13 \%$. In contrast, even though the maximum allowable capacity of the DG in front of recloser is high, its impact on the loss reduction is rather low, approximately 3-6\%. Similar results can be found for Feeders 3 and 4.

Figure 11 graphically presents the results of Case 3 . The maximum allowable capacity of a DG at each location along the main line is presented by a circle with its value. The size of the circle is related to capacity of a DG.

It is clearly shown that the developed method is a tool for distribution system engineers. A utility officer can quickly calculate the capability of allowing a DG connected to the existing system. This will help the utility officer screen the applied DG projects. For example, Figure 11 shows that if there is a DG request for its connection at node $2 B$, the desired maximum allowable capacity from the utility perspective will be $5.70 \mathrm{MW}$. If the DG is of less capacity, the utility officer will know that such a DG will not cause problem to the existing network in terms of loss, voltage profile, and protection coordination. Nonetheless, a larger capacity of the DG implies that the existing system needs to be modified or upgraded.

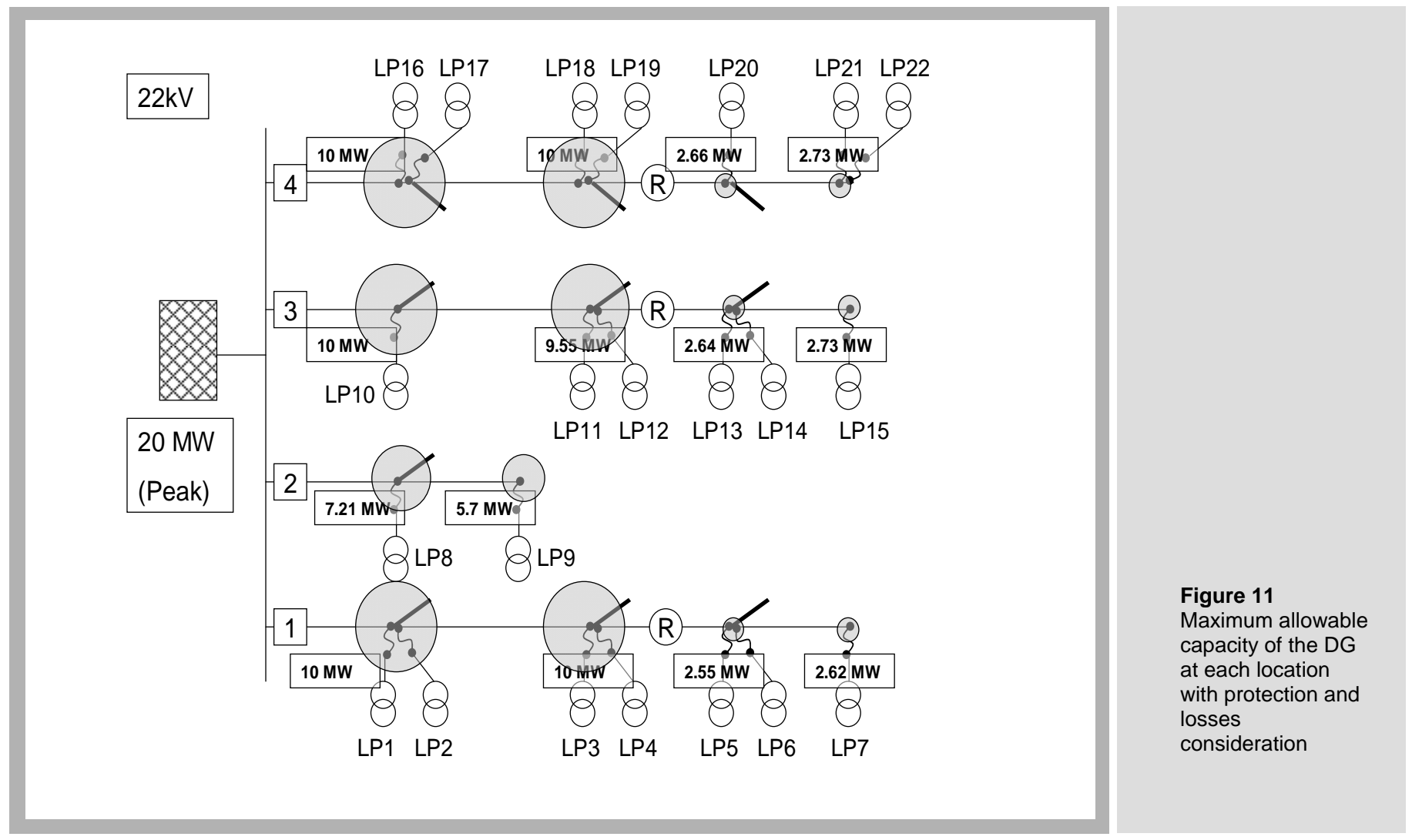

\section{Conclusions}

This paper proposes a methodology to determine the maximum allowable capacity of a DG taking into account voltage, loss, and protection coordination constraints. In obtaining the results, a direct search method is applied with a proper set of constraints related to the DG and the fault locations.

Impacts between loss and protection coordination constraints on the allowable DG capacity were analyzed. The obtained results in this paper show that protection coordination constraint dominates the line loss constraint. If the protection coordination is not considered, the maximum allowable capacity will be larger, but may cause protection coordination failure.

The results also show that maximum allowable DG capacity tends to be of a smaller size for a DG located behind the recloser, compared to the DG connected in front the same recloser. Nonetheless, the smaller size of the DG behind the recloser, which is generally located 
closer to the end of the feeder, tends to have higher impact on system loss reduction than the DG connected in front of the recloser. 


\section{REFERENCES}

[1] M. T. Doyle, "Reviewing the impacts of distributed generation on distribution system protection," IEEE Power Engineering Society Summer Meeting, vol. 1, pp. 103-105, 2002.

[2] S. Junlakarn, "Optimal sizing of distributed generators in consideration of impacts on protection coordination using genetic algorithms." M.S. thesis, Chulalongkorn University, Bangkok, Thailand, 2006.

[3] P. P. Barker and R. W. De. Mello, "Determining the impact of distributed generation on power system: Part 1 - Radial distribution systems," IEEE Power Engineering Society Summer Meeting, vol. 3, pp. 1645-1656, 2000.

[4] N. Jenkins, R. Allan, P. Crossley, D. Kirschen, and G. Strbac, Embedded Generation: The Institution of Electrical Engineers, 2000.

[5] J. Gers and E. Holmes, Protection of Electricity Distribution Networks, 2nd ed. Herts, UK: The Institution of Engineering and Technology, Institution of Electrical Engineers, 2004.

[6] Short-Circuit Calculations: A Handbook to Accompany the Online Short-Circuit Calculation Program Aug. 25, 2006. [Online]. Available: http://www.arcadvisor.com.

[7] The Institute of Electrical and Electronics Engineers, "IEEE Standard for Interconnecting Distributed Resources with Electric Power Systems," IEEE Standard 1547-2003, 2003.

[8] H. Saadat, Power System Analysis. Boston: McGraw-Hill, 1999.

[9] I. Kasikci, Short Circuits in Power Systems: A Practical Guide to IEC 60909. Weinheim: Wiley-VCH, 2002.

[10] T. N. Boutsika and S. A. Papathanassiou, "Short-circuit calculation in networks with distributed generation," Electric Power Systems Research, vol. 78, no. 7, pp. 1181-1191, 2008.

[11] R. N. Allan, R. Billinton, I. Sjarief, L. Goel, and K. S. So, "A reliability test system for educational purposes-basic distribution system data and results," IEEE Transaction on Power Systems, vol. 6, pp. 813-820, 1991.

[12] J. L. Blackburn and T. J. Domin, Protective Relaying Principles and Applications, 3rd. ed. Boca Raton: CRC Press, 2007.

[13] ALSTOM, Network Protection and Automation Guide, 3rd. ed. Levallois-Perret: ALSTOM, 2002.

[14] R. D. Zimmerman, C. E. Murillo-Sánchez,and D.Gan, "MATPOWER: A MATLAB Power System Simulation Package," 2007. [Online]. Available: http://www.pserc.cornell.edu/matpower. 